\title{
Bio-designing of Culture Conditions for Chlorella vulgaris Using Response Surface Methodology
}

\author{
Özlem Karaveli (D), İrem Deniz' ${ }^{1}$ (D)
}

Cite this article as: Karaveli, O. \& Deniz, I. (2020). Bio-designing of culture conditions for Chlorella vulgaris using response surface methodology Aquatic Sciences and Engineering, 35(4), 110-8.

ORCID IDs of the author: Ö.K. 0000-0001-6693-2626; i.D. $0000-0002-1171-8259$

${ }^{1}$ Manisa Celal Bayar University, Faculty of Engineering, Department of Bioengineering, Manisa, Turkey

\section{Submitted:}

29.04.2020

Revision Requested: 24.05.2020

Last Revision Received: 24.05.2020

\section{Accepted:}

30.05.2020

Online published:

18.08.2020

Correspondence:

Irem Deniz

E-mail:

iremdenz@gmail.com

(C) Copyright 2020 The Author(s) Available online at

https://dergipark.org.tr/ase

\begin{abstract}
Microalgae are microscopic organisms and show a geographical distribution depending on the physical, dynamic, and chemical factors of the environment. These factors are mostly important for attachment and development of microalgae. Substrate, temperature, light, agitation, and turbidity can be given as examples of physical factors, whereas salinity, $\mathrm{pH}$ value, and vitamins can be categorized as chemical factors. In this study, the optimization of Chlorella vulgaris production was carried out by response surface methodology (RSM) using two factors of agitation rate (100-250 $\mathrm{rpm}$ ) and nitrogen source concentration (1-4 g/L) in the cultivation of BG11 medium. Moreover, the usage of urea instead of $\mathrm{NaNO}_{3}$ was investigated and discussed.
\end{abstract}

Keywords: Chlorella vulgaris, Response surface methodology, Optimization, Urea

\section{INTRODUCTION}

Microalgae are distributed across the tree of life with the most genetic diversity on the planet and they are members of a group of aquatic organisms of the kingdom Protista predominantly (Barkia et al., 2019). Thus, the capability of microalgae and their products have been studied for centuries.

Industrial microalgae cultivation will provide to the development of a sustainable large-scale production for biomass as well as its products. The industrial microalgae production potential was shown for various species of microalgae (Støttrup and McEvoy, 2008). However, there are several challenges to run commercial trials. The most affecting factors for those challenges are less biomass concentrations and insufficient information on growth conditions (Khan et al., 2018). Microalgae can be cultured under different conditions depending on the physical, dynamic, and chemical factors of the environment. Substrate, temperature, light, and turbidity can be given as examples of physical fac- tors. Salinity, $\mathrm{pH}$ value, and vitamins can be categorized as chemical factors whereas, agitation and pressure are dynamic factors. Those factors are mostly important for the growth of industrial-scale biomass production.

Photosynthesis occurs in almost all microalgae owing to the chlorophyll-a and much of what is known about photosynthesis was discovered firstly by studying green alga. Chlorella sp. Chlorella sp. has a high amount of lipids and fatty acids, carbohydrates, peptides and proteins, inorganic minerals, phenolic compounds, and vitamins in its structure (Becker, 2007; Hariskos and Posten, 2014; Yeh et al., 2010). C. vulgaris has high photosynthetic capacity with regard to vascular plants due to the high concentration of chlorophyll-a. Moreover C. vulgaris is rich in B-group vitamins, especially B12, which are vital for the formation and development of blood cells. Owing to these rich contents, C. vulgaris can be used in cosmetics, wastewater treatment, pharmaceuticals, fruit and vegetable preservatives, tablets, powders, nectar, and noodles (Chisti, 2007; Priyadarshani and Rath, 2012; 
Stolz and Obermayer, 2005). Chlorella sp., therefore, is considered a promising feedstock for several sustainable and value-added bioproducts in various cultivation modes for renewable energy, food, biopharmaceutical, and nutraceutical manufacturing.

Nitrogen source concentration and agitation rates play major roles in C. vulgaris cultivation. Different works that have aimed to observe the effect of nitrogen source concentration show that there is an inverse proportion between $C$. vulgaris production and the present nitrogen source concentration in a growth medium. As reported earlier, the $C$. vulgaris growth rate increased up until saturation levels, while the nitrogen source concentration in a growth medium decreased (Tam and Wong, 1996). Moreover, it was observed that the maximum level of lipid contents of $C$. vulgaris depended on when microalgal cultivation was achieved, and when the nitrogen source concentration was at a minimum level (Converti et al., 2009). In addition, microalgae can be damaged at high agitation rates because of the leakage of important chemicals from within the cell (Sacasa Castellanos, 2013). This study was aimed at determining the optimization of $C$. vulgaris production. The optimization of $C$. vulgaris production was provided by Response Surface Methodology (RSM) using two factors of agitation rate (100-250 rpm) and nitrogen source concentration (1-4 g/L) in the cultivation of BG11 medium. Moreover, the usage of urea instead of $\mathrm{NaNO}_{3}$ was investigated and discussed.

\section{MATERIALS AND METHODS}

\section{Maintenance and growth conditions of $C$. vulgaris}

C. vulgaris was obtained from EGE MACC, Izmir-Turkey. The sample was incubated for three days in a refrigerated shaker incubator at $22 \pm 2{ }^{\circ} \mathrm{C}$ with a stirring speed of $100 \mathrm{rpm}$ under continuous illumination that measured as 320 lux. At the end of the third day, the stock culture was transferred into two $250 \mathrm{~mL}$ Erlenmeyers which contained $100 \mathrm{ml}$ of sterile BG11 medium prepared under laboratory conditions and used for cultivation of $C$. vulgaris as equal amounts to prepare the inoculum culture aseptically. Both Erlenmeyers were allowed to incubate at $22 \pm 2^{\circ} \mathrm{C}$, under a yellow light in the incubator, at a stirring rate of $100 \mathrm{rpm}$ for ten days. The ten-day-old cultures were used as inoculum at $10 \%$ volume for all experiments.

The C. vulgaris strains were cultured in the $250 \mathrm{~mL}$ Erlenmeyer containing $90 \mathrm{~mL}$ growth medium in the refrigerated shaker incubator under a temperature of $22 \pm 2^{\circ} \mathrm{C}$ at different concentrations of nitrogen and different agitation rates. The $C$. vulgaris strains were incubated either for 8 days when $\mathrm{NaNO}_{3}$ was used as a nitrogen source type or for 10 days when urea was used as a nitrogen source type. Illumination was provided by refrigerated shaker incubator (Mikrotest MCS-55). Irradiance was measured with a Luxmeter (Benetech Gm1010 Digital Light Meter).

\section{RSM and optimization studies}

C. vulgaris production optimization was provided using 22 full factorial experiment designs with five replicates at a central point (175 rpm and $2.5 \mathrm{~g} / \mathrm{L}$ ) according to Central Composite Design (CCD) by the Response Surface Methodology (RSM) using Design Experiment Pro 7.0.0. $\mathrm{NaNO}_{3}$ and urea were used as nitrogen source types. The range of nitrogen source concentration and agitation rates selected were 1-4 g/L and 100-250 rpm respectively. Determined factors' codes, ranges, and their levels can be seen in Table 1. There were five different agitation rates; A-rpm $(69,100,175,250,281)$ and five different nitrogen source concentrations; and B-g/L $(0.37,1,2.5,4,4.62)$ was studied for $C$. vulgaris production optimization. It was considered that these levels have potential effects on response function; and biomass concentration (Y, mg/L). The CCD can be seen in Table 2. In total, 13 experimental sets were used for determination of optimum level selected factors. All experiments were performed in duplicate and the average values of experimental sets were recorded.

Table 1. Experimental range and levels of the independent variables.

\begin{tabular}{|c|c|c|c|c|c|c|}
\hline \multirow{2}{*}{$\begin{array}{l}\text { Independent } \\
\text { Variables }\end{array}$} & \multirow{2}{*}{$\begin{array}{l}\text { Symbol } \\
\text { Coded }\end{array}$} & \multicolumn{5}{|c|}{ Coded Levels } \\
\hline & & $-\alpha$ & -1 & 0 & +1 & $+\alpha$ \\
\hline $\begin{array}{l}\text { Agitation rate } \\
\text { (rpm) }\end{array}$ & $A$ & 69 & 100 & 175 & 250 & 281 \\
\hline $\begin{array}{l}\text { Nitrogen source } \\
\text { concentration } \\
\text { (g/L) }\end{array}$ & $B$ & 0.37 & 1 & 2.5 & 4 & 4.62 \\
\hline
\end{tabular}

Table 2. $\quad$ CCD for C. vulgaris.

\begin{tabular}{cccc}
\hline $\begin{array}{c}\text { Number of } \\
\text { Experimental } \\
\text { Sets }\end{array}$ & $\begin{array}{c}\text { Factor } 1 \\
\text { Agitation } \\
\text { Rate (rpm) (A) }\end{array}$ & $\begin{array}{c}\text { Factor 2 } \\
\text { Nitrogen Source } \\
\text { Concentrations (g/L) (B) }\end{array}$ \\
\cline { 3 - 4 } & & NaNO $_{3}$ & Urea \\
\hline 1 & 281 & 2.5 & 2.5 \\
2 & 69 & 2.5 & 2.5 \\
3 & 175 & 2.5 & 2.5 \\
4 & 175 & 0.37 & 0.37 \\
5 & 175 & 2.5 & 2.5 \\
6 & 175 & 2.5 & 2.5 \\
7 & 250 & 4 & 4 \\
8 & 175 & 2.5 & 2.5 \\
9 & 100 & 1 & 1 \\
10 & 100 & 4 & 4 \\
11 & 175 & 4.6 & 4.6 \\
12 & 175 & 2.5 & 2.5 \\
13 & 250 & 1 & 1
\end{tabular}

In accordance with these experimental sets, the growth medium where C. vulgaris was cultivated prepared as $100 \mathrm{~mL}$ into the $250 \mathrm{~mL}$ Erlenmeyer without any $\mathrm{pH}$ value. The difference between the growth medium and the original BG11 growth medium was the nitrogen source type and the nitrogen concentration. Then, $10 \mathrm{ml}$ of each growth medium was pipetted into two different schott bottles according to the type of nitrogen source. Ten $\mathrm{mL}$ of C. vulgaris was inoculated into the $250 \mathrm{~mL} \mathrm{Er-}$ 
lenmeyer which contained $90 \mathrm{~mL}$ growth medium. In addition, a new inoculum culture was prepared by adding $90 \mathrm{~mL}$ of BG11 growth medium and $10 \mathrm{~mL}$ of $C$. vulgaris to an Erlenmeyer for use in subsequent sowing. Inoculated Erlenmeyer and newly prepared inoculum culture were put into the shaking incubator and cultivated in different periods which changed according to the type of nitrogen source at $22 \pm 2{ }^{\circ} \mathrm{C}$ according to the experimental set-up. The Erlenmeyer which contained $\mathrm{NaNO}_{3}$ as a nitrogen source was cultivated for eight days, The Erlenmeyer which contained urea as a nitrogen source and inoculum culture were cultivated for ten days.

The mathematical relationship of these independent variables on response can be approximated by a quadratic polynomial equation as can be seen in Equation 1:

$$
\mathrm{Y}=\beta_{0}+\beta_{1} \mathrm{~A}+\beta_{2} \mathrm{~B}+\beta_{12} \mathrm{AB}+\beta_{11} \mathrm{~A} 2+\beta_{22} \mathrm{~B} 2 \text { (1) }
$$

Where $Y$ represents the response variable, $\beta_{0}$ is model constant, $\beta_{1}$ and $\beta_{2}$ are linear coefficients, $\beta_{12}$ is interaction effect coefficient, $\beta_{11}$ and $\beta_{22}$ are quadratic coefficients, $A$ and $B$ are the coded levels of independent variables. The terms $A B, A^{2}$ and $B^{2}$ represents the interaction term between factors and quadratic terms of factors respectively. The equation (1) expresses the relationship between predicted response value and the independent variables in coded values. The quality of the developed model was determined by value of correlation value $\left(R^{2}\right)$. Analysis of variance (ANOVA) was used for evaluation of the statistical significance of the model with values of regression and mean square of residual error (Deniz et al., 2015).

\section{Dry-weight analysis}

After two replicated productions of $C$. vulgaris for each experimental set up, the dry weight of these was measured by using filter paper. Firstly, the filter paper which was dried at $60^{\circ} \mathrm{C}$ for one night in vacuum oven (Daihan Wov-70) and cooled in desiccators for 45 minutes was tarred by using precision scales (Shimadzu Atx224). Then it was moistened with $5 \mathrm{~mL}$ of distilled water. Secondly, a $50 \mathrm{~mL}$ sample was taken from the Erlenmeyer which was measured and dropped onto the filter paper slowly. Lastly, $5 \mathrm{~mL}$ of distilled water was dropped onto the filter paper again. These wetting and dropping procedures were performed by using a vacuum pump (Diaphragm Lh-185Lh). Then, the filter paper was dried at $60{ }^{\circ} \mathrm{C}$ for one night to reach a constant weight and cooled in desiccators for 45 minutes the next day. After these procedures, the filter paper was weighed again, and dry weight calculations were made. The results were recorded to an experimental design table.

\section{RESULTS AND DISCUSSION}

This set of experiments were designed by CCD using RSM and evaluated the effects of factors (agitation rateand nitrogen source concentration) on the production of C. vulgaris. As seen in Table 3, the range of factors selected were 100-250 rpm and 1-4 $\mathrm{g} / \mathrm{L}$ at the end of the literature review, biomass concentration which changed depending on selected factors which ranged from 0.013 to $0.55 \mathrm{mg} / \mathrm{L}$ and 0.025 to $0.132 \mathrm{mg} / \mathrm{L}$ for $\mathrm{NaNO}_{3}$ and urea respectively. The $C$. vulgaris production was performed five times at the central point (175 rpm and $2.5 \mathrm{~g} / \mathrm{L}$ ) of factors for optimization. According to the results of these five replications, the average values of biomass concentration were calculated as 0.32 $\mathrm{mg} / \mathrm{L}$ for production which contained $\mathrm{NaNO}_{3}$ as a nitrogen source type in growth media and $0.054 \mathrm{mg} / \mathrm{L}$ for urea. In addition, the maximum and minimum values of biomass concentration were reported as 0.013-0.55 mg/L and 0.025-0.132 mg/L for $\mathrm{NaNO}_{3}$ and urea respectively.

Table 3. Experimental design matrix and experimental results.

\begin{tabular}{|c|c|c|c|c|}
\hline \multirow{2}{*}{ Runs } & \multirow{2}{*}{$A(r p m)$} & \multirow{2}{*}{$B(g / L)$} & \multicolumn{2}{|c|}{$\begin{array}{l}\text { Biomass concentration } \\
\text { (mg/L) }\end{array}$} \\
\hline & & & $\mathrm{NaNO}_{3}$ & Urea \\
\hline 1 & 281 & 2.5 & $0.05 \pm 0.01$ & $0.036 \pm 0.00$ \\
\hline 2 & 69 & 2.5 & $0.022 \pm 0.00$ & $0.06 \pm 0.02$ \\
\hline 3 & 175 & 2.5 & $0.4 \pm 0.02$ & $0.032 \pm 0.00$ \\
\hline 4 & 175 & 0.37 & $0.3 \pm 0.03$ & $0.132 \pm 0.04$ \\
\hline 5 & 175 & 2.5 & $0.3 \pm 0.01$ & $0.04 \pm 0.01$ \\
\hline 6 & 175 & 2.5 & $0.3 \pm 0.01$ & $0.03 \pm 0.00$ \\
\hline 7 & 250 & 4 & $0.014 \pm 0.01$ & $0.01 \pm 0.00$ \\
\hline 8 & 175 & 2.5 & $0.4 \pm 0.01$ & $0.1 \pm 0.03$ \\
\hline 9 & 100 & 1 & $0.072 \pm 0.01$ & $0.094 \pm 0.04$ \\
\hline 10 & 100 & 4 & $0.084 \pm 0.00$ & $0.01 \pm 0.01$ \\
\hline 11 & 175 & 4.6 & $0.55 \pm 0.01$ & $0.025 \pm 0.00$ \\
\hline 12 & 175 & 2.5 & $0.2 \pm 0.21$ & $0.02 \pm 0.03$ \\
\hline 13 & 250 & 1 & $0.013 \pm 0.01$ & $0.1 \pm 0.03$ \\
\hline
\end{tabular}

\section{Response Surface Methodology For Biomass Concentration For $\mathrm{NaNO}_{3}$}

The biological, chemical, and physical parameters play important roles in biomass production. In this study, the agitation rate and nitrogenous source concentration were physical parameters which played a dynamic role in the stimulation of biomass production and the factor ranges selected were 100-250 rpm and 1-4 $\mathrm{g} / \mathrm{L}$ respectively.

The statistical testing of the model of $C$. vulgaris biomass production in a growth medium containing $\mathrm{NaNO}_{3}$ was done by Fisher's $F$ test for ANOVA as shown in Table 4. The $F$ value was shown as 4.72 and where the $p$ value was less than 0.05 with 0.0298 value, there was only a 2.98 chance that a "Model F Value" this large could occur due to noise. The values of $F$ and $p$ implies that the quadratic model was significant for production optimization of C. vulgaris. "Lack of fit F value" of 3.09 implied that the "Lack of fit" was not significant relative to pure error. There was a $14.99 \%$ chance that a "Lack of Fit F Value" this large could occur due to noise. The insignificance of "Lack of fit" value was a desired circumstance for convergence of the model as close to reality as possible. Statistically, the significance of the model and the insignificance of "Lack of fit" value indicated that the model was appropriate.

As seen in Table 4, the regression coefficient $R^{2}$ of 0.7025 value indicated that the regression model represented $70.25 \%$ of the experimental results and expressed a good fit response. The quality of fit explained by the model given by the multiple coefficient of determined $R^{2}$ value and if $R^{2}>0.7$ insured, the model 
Table 4. Analysis of variance (ANOVA) of the model for biomass concentration for $\mathrm{NaNO}_{3}$.

\begin{tabular}{|c|c|c|c|c|c|}
\hline Source & Sum of Squares & Degree of Freedom & Mean Square & F-Value & $p>F$ \\
\hline Model & 0.27 & 4 & 0.068 & 4.72 & 0.0298 \\
\hline $\begin{array}{c}\text { Factor A } \\
\text { Agitation Rate }\end{array}$ & $9.991 \mathrm{E}-004$ & 1 & $9.991 \mathrm{E}-004$ & 0.070 & 0.7984 \\
\hline $\begin{array}{c}\text { Factor B } \\
\text { Nitrogen Source Con- } \\
\text { centration }\end{array}$ & 0.017 & 1 & 0.017 & 1.17 & 0.3104 \\
\hline Residual & 0.11 & 8 & 0.014 & & \\
\hline Lack of Fit & 0.087 & 4 & 0.022 & 3.09 & 0.1499 \\
\hline Pure Error & 0.028 & 4 & 7.000E-003 & & \\
\hline Correlation Total & 0.39 & 12 & & & \\
\hline
\end{tabular}

was suitable and adequate in biological production (Hanrahan et al., 2007). By adding factors to the model, the $R^{2}$ value increased regardless of factors significant or non-significant (Montgomery, 2001; Myers et al., 2016). Generally, although incensement of $R^{2}$, the adjusted $R^{2}$ (adj. $R^{2}$ ) value did not increase by the addition of factors to the model. Large differences between $R^{2}$ and adj. $R^{2}$ indicated that the model included non-significant terms. The adj. $R^{2}$ coefficient showed that significance of the model was high (Myers et al., 2016). In addition, the adj. $R^{2}$ value increased by deleting unnecessary factors of the model (Fermoso et al., 2010; Mazaheri et al., 2010). In this study, the adj. $R^{2}$ value was 0.5538 which eliminated non-significant terms from the model.

Adequate precision value (adeq. precision) measures the noise level of signals. There are circumstances in which an adequate precision value of more than 4 is desirable and this study determined that a model can be used to navigate the design space with an adeq. precision of 6,179 value. If the predicted $R^{2}$ is less than 0 (in this study with 0.2293 value), then the overall mean is a better predictor of response than the model.

The effect of factors on C. vulgaris production are expressed mathematically in a quadratic polynomial equation, Equation 2, for a growth medium including $\mathrm{NaNO}_{3}$. In Equation 2, $Y$ was the expected response; biomass concentration ( $\mathrm{mg} / \mathrm{L}), A$ and $B$ were the coded values of factors; agitation rate (rpm) and nitrogenous source concentration $(\mathrm{g} / \mathrm{L})$ respectively.

$$
Y=0.32-0.011 \times A+0.046 \times B-2.750 E-003 x A \times B-0.19 x A^{2}(2)
$$

It is clear that the most affecting factor is $A^{2}$, in other words the square of the agitation rate, on biomass concentration and the square of the agitation rate is followed by nitrogenous source concentration, agitation rate, and interaction of factors respectively with regard to circumstances of terms in Equation 2 and Table 4.
The relationship between obtained biomass concentration response values from optimization studies which were performed in accordance with experimental sets and calculated biomass concentration results by using the Equation 2 can be seen in Figure 1. The optimum conditions described by the model as the point in which the biomass concentration values which were obtained by optimization studies close to the calculated biomass concentration results by using the Equation 2. In Figure 2, the effect of the interaction of factors selected which were the agitation rate and nitrogenous source concentration and change in range of 100- $250 \mathrm{rpm}$ and 1-4 g/L respectively, on biomass concentration can be seen. The shape of the response surface showed an interaction between these two factors. The weakest effect on the response was observed for the nitrogenous source concentration with $1 \mathrm{~g} / \mathrm{L}$ value, regardless of the maximum and minimum levels of agitation rate. In response surface 3D plot, the effect of the agitation rate could be seen clearly. The obtained biomass concentration response values from optimization studies were related closely with the agitation rate in which $C$. vulgaris productions were performed.

In this study, the level of physical parameters of agitation rate and nitrogenous source concentration were fixed as low and high, in the range of -1 to +1 and the maximum value of the response was aimed. All relevant factors were limited as seen in Table 5 for production optimization studies of C. vulgaris. The C. vulgaris production optimization solutions corresponded to 172 rpm and $4 \mathrm{~g} / \mathrm{L}$ for agitation rate and nitrogenous source concentration respectively in regards to response at maximum desirability and predictability. Furthermore, the amount of biomass concentration obtained at the end of the production of $C$. vulgaris at optimum conditions were $0.370 \mathrm{mg} / \mathrm{L}$ with an appropriate predicted value with the desirability of 0.666 . According to the model seen in Equation 2, optimum conditions of biomass production of $C$. vulgaris were determined as $172 \mathrm{rpm}$ agitation rate and $4 \mathrm{~g} / \mathrm{L}$ nitrogenous source concentration as $\mathrm{NaNO}_{3}$. 


\subsection{Response surface methodology for biomass concentra- tion for urea}

The physical parameters effective on the production of C. vulgaris were selected as agitation rate and nitrogenous source concentrations varying from 100-250 rpm and 1-4 g/L respectively. Each ex-

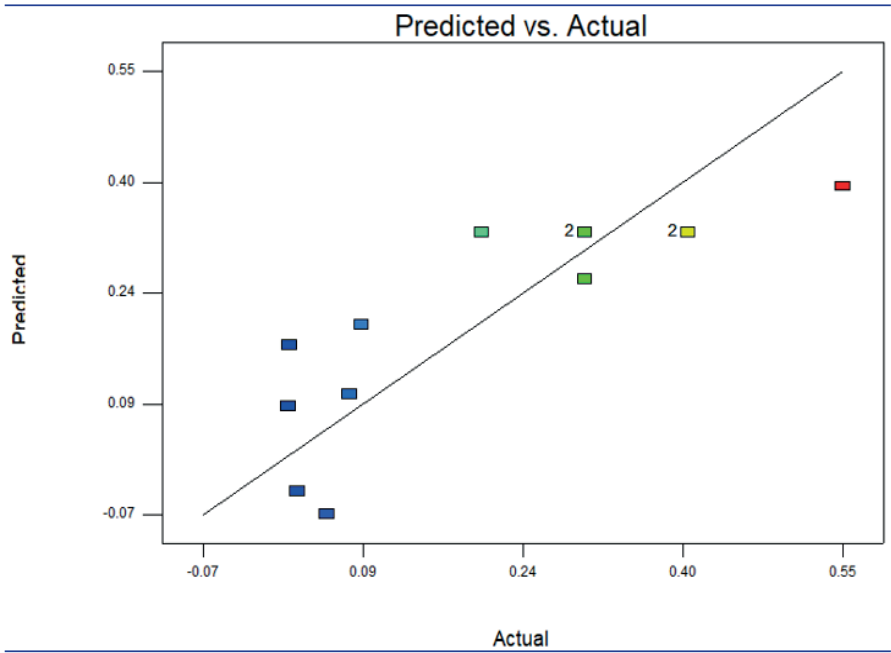

Figure 1. The relationship between performed optimization studies values and calculated values for C. vulgaris biomass concentration.

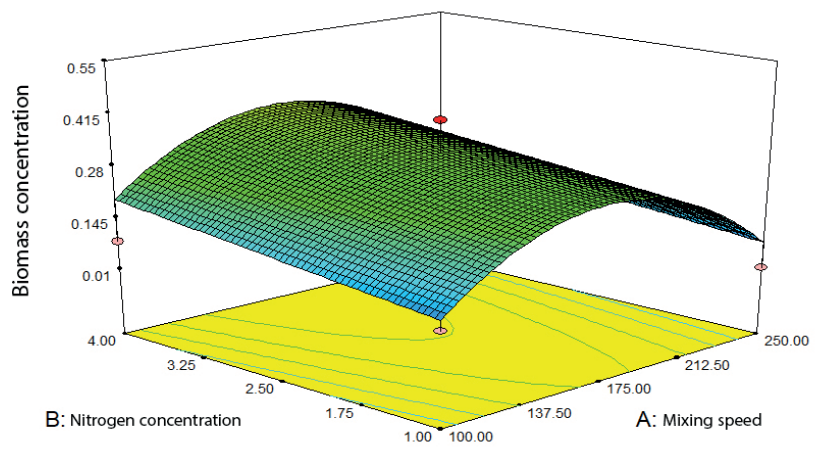

Figure 2. The response surface 3D plot of agitation rate and nitrogenous source concentration effects on $C$. vulgaris biomass concentration. perimental set seen in Table 2 were studied twice for determining the optimum production conditions of $C$. vulgaris. As seen in Table 6 , the variance analysis (ANOVA) used for response analysis at the end of the different combinations of factors which was effective on C. vulgaris production. According to this, the biomass concentration model $F$ value of 4.60 implies the model is significant and that there is only a 3.52\% chance that a "Model F-Value" this large could occur due to noise. Values of "Prob> f" less than 0.05 indicate model terms are significant. The $p$ value associated with the $F$ value is used to determine whether the $F$ value was large enough to show statistical significance (Jaliliannosrati et al., 2013). The "Lack of Fit F-value" of 0.15 implies the Lack of Fit is not significant relative to pure error. There is a $92.53 \%$ chance that a "Lack of Fit F-value" this large could occur due to noise. Non-significant lack of fit is good for convergence to reality of the model. According to this study, the statistical significance of the model and the insignificance of lack of fit implies that the model is significant.

In this study, $\mathrm{R}^{2}$ value was 0.7668 and it implies that a regression model did not correspond to the experimental results in ratio of $23.32 \%$. The adjusted $R^{2}$ value was high with 0.6003 and the model was highly significant.

If there are p values lower than 0.0001 level in an analysis of variance, then a quadratic polynomial model has high significance and it is enough for the interrelated independent factors and responses (Guo et al., 2012). The p value of the model was 0.0352. According to the model, the $p$ value of factors which affected biomass and coded as $A$ and $B$ were 0.0027 and 0.9093 respectively. In this situation, although factor $A$ is assumed as significant for the model because the $p$ value was lower than 0.05 , factor $B$ was insignificant because the $p$ value was greater than 0.1 . In addition to that, the interaction coefficient term of $A B$ was insignificant because the $p$ value was higher than 0.05. In this situation, individual effects of factors were greater than the effect of factor interaction on C. vulgaris biomass concentration and the most effect was caused by factor $B$.

When insignificant terms are decreased in the model, an improvement was on the carpet. The coefficient variation was high with a 47.95 value and low values of coefficient variation were needed of a high precision degree in providing the experimental data's reliability. Noise ratio of signals were measured by using an adequate precision value with a desired value not greater than 4 . In this study, the adequate precision value was 6.859. For this reason, the model can be used for 3D design. The predicted $R^{2}$ value was 0.5058 .

The growth medium which included urea as a nitrogenous source type, the effects of selected factors of agitation rate

Table 5. Optimum conditions for maximum biomass concentrations of C. vulgaris for $\mathrm{NaNO}_{3}$.

\begin{tabular}{lcccc}
\hline Factors-Responses & Goal & Lower Limit & Upper Limit & $\begin{array}{c}\text { Optimum conditions for } \\
\text { C. vulgaris }\end{array}$ \\
\hline $\begin{array}{l}\text { Agitation } \\
\text { rate, } A,(r p m)\end{array}$ & Is in range & 100 & 250 & 172.27 \\
$\begin{array}{l}\text { Nitrogenous source } \\
\text { concentrations, } B,(g / L)\end{array}$ & Is in range & 1 & 4 & 4 \\
$\begin{array}{l}\text { Biomass concentration of } \\
\begin{array}{l}\text { C. vulgaris }(\mathrm{mg} / \mathrm{L})\end{array}\end{array}$ & Maximize & 0.013 & 0.55 & 0.370
\end{tabular}


Table 6. $\quad$ Analysis of variance (ANOVA) of the model for biomass concentration for urea.

\begin{tabular}{lccccc}
\hline Source & Sum of Squares & Degree of Freedom & Mean Square & F-Value & $p>F$ \\
\hline Model & 0.015 & 5 & $2.973 E-003$ & 4.60 & 0.0352 \\
Factor A & $9.759 E-005$ & 1 & $9.759 E-005$ & 0.15 & 0.7090 \\
$\begin{array}{l}\text { Agitation Rate } \\
\text { Factor B }\end{array}$ & & & & \\
Nitrogen Source & 0.013 & 1 & 0.013 & 20.48 & 0.0027 \\
Concentration & & & & \\
AB & $9.000 E-006$ & 1 & $9.000 E-006$ & 0.014 & 0.9093 \\
$A^{2}$ & $2.827 E-006$ & 1 & $2.827 E-006$ & $4.377 E-003$ & 0.9491 \\
$B^{2}$ & $1.485 E-003$ & 1 & $1.485 E-003$ & 2.30 & 0.1732 \\
Residual & $4.521 E-003$ & 7 & $6.459 E-004$ & & 0.15 \\
Lack of Fit & $4.538 E-004$ & 3 & $1.513 E-004$ & & 0.9253 \\
Pure Error & $4.067 E-003$ & 4 & $1.017 E-003$ & & \\
Standard Deviation & 0.025 & $R^{2}$ & 0.7668 & & \\
Average & 0.053 & Adjusted $R^{2}$ & 0.6003 & & \\
C.V.\% & 47.95 & Predicted $R^{2}$ & 0.5058 & &
\end{tabular}

and nitrogenous source concentration and coded as $A$ and $B$ on C. vulgaris production was indicated in a second order polynomial equation which was obtained by using multiple regression analysis, Equation 3, which can be used for calculations of predicted response value with any combination of relevant factors in experimental ranges. In Equation 3, $Y$ is the predicted response; biomass concentration ( $\mathrm{mg} / \mathrm{L}$ ), $A$ and $B$ are coded factors; agitation rate (rpm) and nitrogenous source concentration $(\mathrm{g} / \mathrm{L})$ respectively.

$$
\begin{gathered}
Y=0.44-3.493 E-003 \times A-0.041 \times B-1.500 E-003 \times A \times B- \\
6.375 E-004 \times A^{2}+0.015 \times B^{2}(3)
\end{gathered}
$$

According to the coefficients of terms in Equation 3, the p value of $B$ was small and this showed that the dominant factor on biomass concentration was nitrogenous source concentration followed by the square of nitrogenous source concentrations, agitation rate, and interactions of factors which coded as $A$ and $B$ and lastly, the square of agitation rate.

Biomass concentration values obtained at the end of calculations by using Equation 3 and biomass concentration value obtained at the end of the optimization studies performed according to the experimental sets interaction given in Figure 3. Biomass concentration values obtained from performed optimization studies and predicted biomass concentration values calculated by using Equation 3 were close to each other.

The individual and interaction effects of independent factors which were selected as agitation rate and nitrogenous source concentration and affect to the biomass concentrations of $C$. vulgaris can be seen as a 3D response surface in Figure 4 by using the Design Expert in range of 100-250 rpm and 1-4 g/L respectively. In 3D design, the inconvenience of a factors range which affected $C$. vulgaris production can be seen. There was an inverse proportion between biomass concentration obtained at the end of the performed optimization stud-

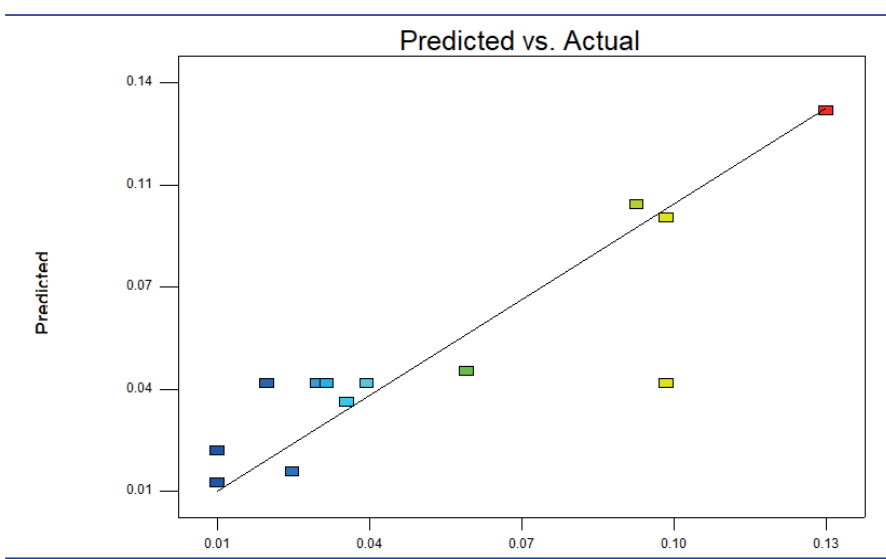

Figure 3. Interaction between biomass concentration values of performed studies and predicted and calculated.

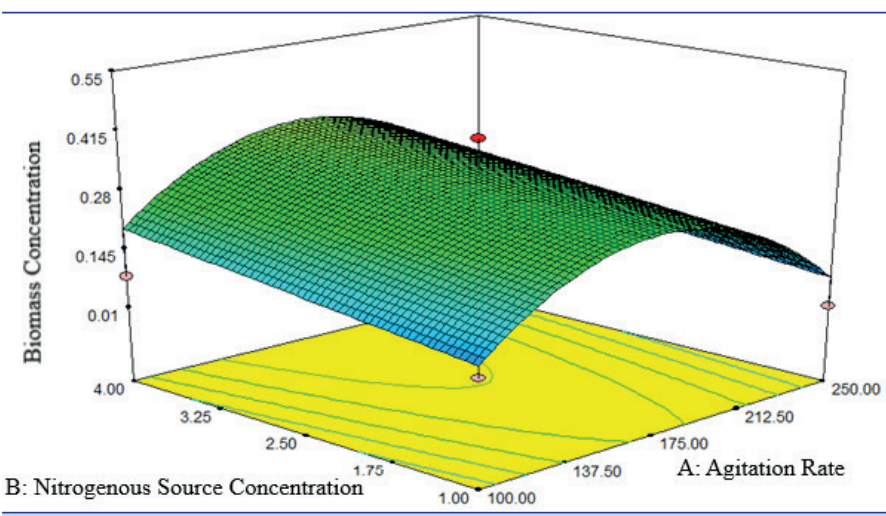

Figure 4. 3D design of agitation rate and nitrogenous source concentration effects on biomass concentration of C. vulgaris. 
ies and present nitrogenous source (urea) concentration regardless of agitation rate values, such that the maximum level of response obtained at minimum level of nitrogenous source concentration likewise minimum level of response reported at maximum level of nitrogenous source concentration. Despite this situation, it was understood that when urea was used as a nitrogenous source in growth medium, the agitation rate did not affect the biomass.

In this study, the maximum response was aimed and the selected physical variables of agitation rate and nitrogenous source (urea) concentration values were fixed in a range -1 (low) to +1 (high). The C. vulgaris production optimization solutions were determined as $100 \mathrm{rpm}$ and $1 \mathrm{~g} / \mathrm{L}$ for agitation rate and nitrogenous source concentration respectively because of the maximum desirability and predictability value of response as seen in Table 7. Furthermore, the amount of biomass concentration of $C$. vulgaris at the end of the production of optimum conditions was predicted as $0.101033 \mathrm{mg} / \mathrm{L}$ and it was in agreement with the predicted value, with the relative desirability of 0.746 , in which the model showed high desirability. According to the model, optimum conditions were $100 \mathrm{rpm}$ agitation rate and $1 \mathrm{~g} / \mathrm{L}$ nitrogenous source concentration for C. vulgaris biomass production by using urea as a nitrogenous source type.

In this study, C. vulgaris production optimization was provided by a Response Surface Methodology (RSM) which depended on agitation rate as a nitrogenous source concentration. When $\mathrm{NaNO}_{3}$ was used as a nitrogenous source in growth medium, optimum conditions were determined as $172 \mathrm{rpm}$ and $4 \mathrm{~g} / \mathrm{L}$ in order to obtain maximum C. vulgaris biomass concentration. These optimum conditions were determined as $100 \mathrm{rpm}$ and $1 \mathrm{~g} / \mathrm{L}$ for urea. It is understood from these results, that the agitation rate was mostly effective on biomass concentration described as a response function for growth medium which contained $\mathrm{NaNO}_{3}$ as a nitrogenous source type. If urea was used as a nitrogenous source type in growth medium, the nitrogenous source concentration played a major role in C. vulgaris production in regards to obtained results and the decrease of a present nitrogen source concentration had a positive effect on biomass concentration. In a previous study, maximum lipid productivity of $C$. vulgaris of $247.16 \mathrm{mg} \mathrm{l}^{-1} \mathrm{~d}^{-1}$ was achieved when the concentration of $\mathrm{NaNO}_{3}$ was $2.06 \mathrm{~g} \mathrm{I}^{-1}$ (Xie et al., 2012). However, (Kong et al., 2012) reported the maximum biomass of C. vulgaris yield of $4.28 \mathrm{~g} / \mathrm{L}$ when the concentrations of $\mathrm{KNO}_{3}$ was $1.30 \mathrm{~g} / \mathrm{L}$.

After determination of optimum conditions for maximum level of C. vulgaris biomass concentration, it is understood that the physical parameter which was mostly effective on biomass concentration changes according to the nitrogenous source type such that the mostly effective physical parameter was agitation rate for $\mathrm{NaNO}_{3}$, and nitrogenous source concentration was the most effective physical parameter for urea. Optimum conditions for $C$. vulgaris production were found to be as $100 \mathrm{rpm}$ in BG11 medium supplemented with $1 \mathrm{~g} / \mathrm{L}$ urea instead of $\mathrm{NaNO}_{3}$. The utilization of urea is important because of its accessibility, being non-explosive, having low cost compared to $\mathrm{NaNO}_{3}$

At the end of this study and literature research our study is in accordance with (Tam and Wong, 1996) and (Converti et al., 2009) and the determined optimum agitation rate level was found to be close to the study of (Imamoglu et al., 2014) where the maximum level of protein contents of C. vulgaris obtained $168 \mathrm{rpm}$. In another study, the optimum agitation rate obtained was $150 \mathrm{rpm}$ for maximum level of biomass of C. vulgaris (Razack et al., 2015). Differences between our study and other studies are caused by differences of growth medium used for $C$. vulgaris cultivation, C. vulgaris cultivation temperature, or the period of the incubation. After the optimum conditions were determined, a new C. vulgaris production was performed according to optimum conditions, predicted and obtained values of the results were controlled and validated. In Table 8, potential C. vulgaris biomass concentration values can be obtained at different confidence intervals when predicted result validation was performed at optimum conditions which were determined by using Design Expert. Biomass productions of 0.35 and 0.11 $\mathrm{mg} / \mathrm{L}$ were obtained for $\mathrm{NANO}_{3}$ and urea respectively at optimum conditions. According to the model, the predicted and performed responses were close together and appropriate to ranges thus it showed that the model was validated.

Determined mathematical models should be compatible with the experimental results. In this study, the aim was to show the maximum effects of selected parameters on C. vulgaris biomass concentrations depending on the nitrogenous source type used in C. vulgaris growth medium. This study presented an experimental approach for new research about the optimization of physical process parameters which are effective on C. vulgaris biomass concentrations.

\section{CONCLUSION}

In this study, the optimization of $C$. vulgaris production was performed and the factors which affect the C. vulgaris production were selected as nitrogen source type, nitrogen source concentration, and agitation rate. The optimum conditions of biomass production of C. vulgaris were determined as $172 \mathrm{rpm}$ and $4 \mathrm{~g} / \mathrm{L}$

Table 7. Optimum conditions for optimum C. vulgaris biomass production.

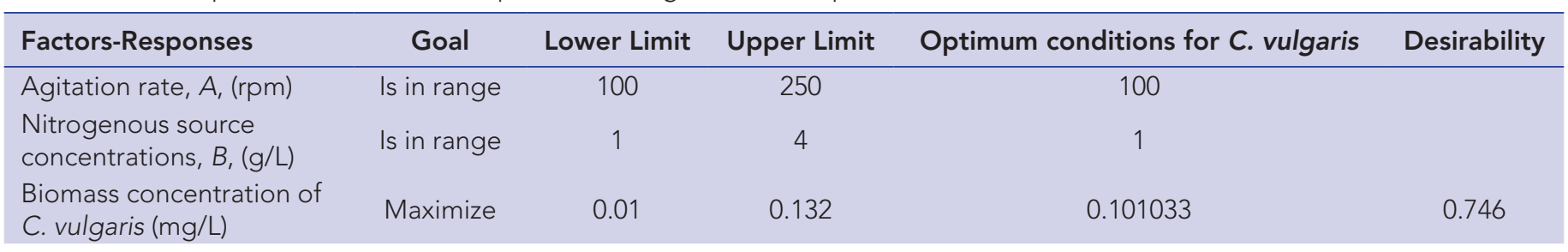


Table 8. Potential C. vulgaris biomass concentrations which can be obtained at the end of the productions at optimum conditions.

\begin{tabular}{|c|c|c|c|c|c|c|c|}
\hline \multicolumn{8}{|c|}{ Predicted Values } \\
\hline Response & Prediction & $\begin{array}{c}\text { Standart Error } \\
\text { Mean }\end{array}$ & $\begin{array}{c}95 \% \\
\text { Confidence } \\
\text { Interval Low }\end{array}$ & $\begin{array}{c}95 \% \\
\text { Confidence } \\
\text { Interval High }\end{array}$ & $\begin{array}{l}\text { Standart Error } \\
\text { Prediction }\end{array}$ & $\begin{array}{c}95 \% \\
\text { Prediction } \\
\text { Interval Low }\end{array}$ & $\begin{array}{c}95 \% \\
\text { Prediction } \\
\text { Interval High }\end{array}$ \\
\hline $\begin{array}{l}\text { C. vulgaris Bio- } \\
\text { mass Concen- } \\
\text { tration (mg/L) }\end{array}$ & 0.370467 & 0.061 & 0.23 & 0.51 & 0.13 & 0.61 & 0.68 \\
\hline \multicolumn{8}{|c|}{ Urea } \\
\hline Response & Prediction & $\begin{array}{c}\text { Standart Error } \\
\text { Mean }\end{array}$ & $\begin{array}{c}95 \% \\
\text { Confidence } \\
\text { Interval Low }\end{array}$ & $\begin{array}{c}95 \% \\
\text { Confidence } \\
\text { Interval High }\end{array}$ & $\begin{array}{l}\text { Standart Error } \\
\text { Prediction }\end{array}$ & $\begin{array}{c}95 \% \\
\text { Prediction } \\
\text { Interval Low }\end{array}$ & $\begin{array}{c}95 \% \\
\text { Prediction } \\
\text { Interval High }\end{array}$ \\
\hline $\begin{array}{l}\text { C. vulgaris Bio- } \\
\text { mass Concen- } \\
\text { tration (mg/L) }\end{array}$ & 0.101033 & 0.020 & 0.054 & 0.15 & 0.032 & 0.024 & 0.18 \\
\hline
\end{tabular}

nitrogenous source concentration as $\mathrm{NaNO}_{3}$. Also, the optimum conditions were $100 \mathrm{rpm}$ and $1 \mathrm{~g} / \mathrm{L}$ nitrogenous source concentration for $C$. vulgaris biomass production by using urea as nitrogenous source type. The study aimed to provide a new nitrogen source for $C$. vulgaris production and also to utilize urea as an alternative substrate in biotechnology owing to the low cost and high accessibility in regard to $\mathrm{NaNO}_{3}$. Because $\mathrm{NaNO}_{3}$ can also be used in agriculture, construction, and the petroleum chemical industry along with the active substance in production of explosive devices. For this reason, availability and conservation of it is very difficult.

\section{Conflict of interests: -}

\section{Ethics committee approval: -}

\section{Funding: -}

Acknowledgments: The authors wish to thank the Scientific and Technological Research Council of Turkey (TUBITAK) under 2209A program with the project number of $1919 \mathrm{~B} 011800856$ for the financial support.

\section{Disclosure: -}

\section{REFERENCES}

Barkia, I., Saari, N., \& Manning, S. R. (2019) Microalgae for high-value products towards human health and nutrition, Marine Drugs, 17(5), 304-305. [CrossRef]

Becker, E. (2007) Micro-algae as a source of protein, Biotechnology Advances, 25(2), 207-210. [CrossRef]

Chisti, Y. (2007) Biodiesel from microalgae, Biotechnology Advances, 25(3), 294-306. [CrossRef]

Converti, A., Casazza, A. A., Ortiz, E. Y., Perego, P., \& Del Borghi, M. (2009) Effect of temperature and nitrogen concentration on the growth and lipid content of Nannochloropsis oculata and Chlorella vulgaris for biodiesel production, Chemical Engineering and Processing: Process Intensification, 48(6), 1146-1151. [CrossRef]

Deniz, I., Imamoğlu, E., \& Dalay, M. C. (2015) Optimization of physical parameters for phycobiliprotein extracted from Oscillatoria agardhii and Synechococcus nidulans/Oscillatoria agardhii ve Synechococcus nidulans türlerinden fikobiliprotein ekstraksiyonu için fiziksel parametrelerin optimizasyonu, Turkish Journal of Biochemistry, 40(6), 481-491. [CrossRef]

Fermoso, J., Gil, M. V., Arias, B., Plaza, M. G., Pevida, C., Pis, J., \& Rubiera, F. (2010) Application of response surface methodology to assess the combined effect of operating variables on high-pressure coal gasification for $\mathrm{H}_{2}$-rich gas production, International Journal of Hydrogen Energy, 35(3), 1191-1204. [CrossRef]

Guo, J., Zhuang, Y., Chen, L., Liu, J., Li, D., \& Ye, N. (2012) Process optimization for microwave-assisted direct liquefaction of Sargassum polycystum C. Agardh using response surface methodology, Bioresource Technology, 120, 19-25. [CrossRef]

Hanrahan, G., Garza, C., Garcia, E., \& Miller, K. (2007) Experimental design and response surface modeling: A method development application for the determination of reduced inorganic species in environmental samples, Journal of Environmental Informatics, 9(2). [CrossRef]

Hariskos, I., \& Posten, C. (2014) Biorefinery of microalgae-opportunities and constraints for different production scenarios, Biotechnology Journal, 9(6), 739-752. [CrossRef]

Imamoglu, E., Demirel, Z., \& Dalay, M. C. (2014) A response surface methodology study for the protein production of Chlorella sp. Int $J$ Adv Chem Engg Biol Sci (IJACEBS), 1, 76-79.

Jaliliannosrati, H., Amin, N. A. S., Talebian-Kiakalaieh, A., \& Noshadi, I. (2013) Microwave assisted biodiesel production from Jatropha curcas I seed by two-step in situ process: Optimization using response surface methodology, Bioresource Technology, 136, 565-573. [CrossRef]

Khan, M. I., Shin, J. H., \& Kim, J. D. (2018) The promising future of microalgae: Current status, challenges, and optimization of a sustainable and renewable industry for biofuels, feed, and other products, Microbial Cell Factories, 17(1), 36. [CrossRef]

Kong, W. B., Hua, S. F., Cao, H., Mu, Y. W., Yang, H., Song, H., \& Xia, C. G. (2012) Optimization of mixotrophic medium components for biomass production and biochemical composition biosynthesis by Chlorella vulgaris using response surface methodology, Journal of the Taiwan Institute of Chemical Engineers, 43(3), 360-367. [CrossRef]

Mazaheri, H., Lee, K. T., Bhatia, S., \& Mohamed, A. R. (2010) Subcritical water liquefaction of oil palm fruit press fiber for the production of bio-oil: Effect of catalysts, Bioresource Technology, 101(2), 745-751. [CrossRef] 
Montgomery, D. C. (2001) Design And Analysis Of Experiments. John Wiley \& Sons. Inc., New York.

Myers, R. H., Montgomery, D. C., \& Anderson-Cook, C. M. (2016) Response surface methodology: Process and product optimization using designed experiments. John Wiley \& Sons Inc., New York.

Priyadarshani, I., \& Rath, B. (2012) Commercial and industrial applications of micro algae-a review, Journal of Algal Biomass Utilization, 3(4), 89-100.

Razack, S. A., Duraiarasan, S., Shellomith, A. S., \& Muralikrishnan, K. (2015) Statistical optimization of harvesting Chlorella vulgaris using a novel bio-source, strychnos potatorum, Biotechnology Reports, 7, 150-156. [CrossRef]

Sacasa Castellanos, C. (2013) Batch and continuous studies of Chlorella vulgaris in photo-bioreactors, Electronic Thesis and Dissertation Repository, 1113.
Stolz, P., \& Obermayer, B. (2005) Manufacturing microalgae for skin care, Cosmetics and Toiletries, 120(3), 99-106.

Støttrup, J., \& McEvoy, L. (2008) Live feeds in marine aquaculture. John Wiley \& Sons. Inc., New York.

Tam, N., \& Wong, Y. (1996). Effect of ammonia concentrations on growth of Chlorella vulgaris and nitrogen removal from media, Bioresource Technology, 57(1), 45-50. [CrossRef]

Xie, T., Sun, Y., Du, K., Liang, B., Cheng, R., \& Zhang, Y. (2012) Optimization of heterotrophic cultivation of Chlorella sp. for oil production, Bioresource Technology, 118, 235-242. [CrossRef]

Yeh, K. L., Chang, J. S., \& Chen, W. M. (2010) Effect of light supply and carbon source on cell growth and cellular composition of a newly isolated microalga Chlorella vulgaris esp-31, Engineering in Life Sciences, 10(3), 201-208. [CrossRef] 